\title{
Guiding Principles for Community Engagement: Reflections on a School-Based Sustainability Project
}

\section{Charlotte Blythe, Niki Harré, Sindra Sharma, Victoria Dillon, Briar Douglas and Amadia Didsbury}

University of Auckland

\begin{abstract}
This article describes an action research project in which community psychologists worked with a school community to promote environmentally sustainable practices. Our research team had five guiding principles: strengths-based, empowerment, role modeling, communication, and measurement and feedback. Here we describe a phenomenological study of how we experienced our principles and how key participants from the school perceived our professional practice. Each research team member completed a self-reflective survey and key staff and students from the school were interviewed. Amongst other benefits, the principles were valuable in promoting coherence within the research team, guiding decision-making and providing a framework for critical reflection. Recommendations are given for researchers and community practitioners interested in initiating sustainability projects with local organizations or using a similar principles-based approach in other collaborative endeavors.
\end{abstract}

Keywords: sustainability, action research, environmental, youth, phenomenology, autoethnography

\section{Introduction}

In this article we reflect on a collaborative project in which we, as university-based community psychologists, worked with members of a local school to establish environmentally sustainable practices at the school. Our research team essentially ran the project for two years, after which it gained momentum at the school and we took a much lesser role. We therefore offer our experience as a success, not so much in making direct change, as by helping inspire the organization we were working with to take ownership of this key issue. From the beginning, we used five principles as our guiding structure. We chose principles with strong empirical and 
theoretical backing, and constantly attempted to align our actions with these. We suggest that these principles acted as an essential guide in motivating us to persist and in the project being taken over by the school. In this paper we describe the rationale for these principles, reflect on our experiences of applying them in the project, and inquire into how our principles were perceived by key participants from the school. Ultimately, we hope to shed light on how principles may be used by researchers and community practitioners to guide their engagement with organizations.

We begin by describing the context for the project. We then introduce our research approach and guiding principles. After outlining how the project operated in 2008 and 2009 we provide analysis and reflection of our principles in action. We conclude with recommendations for the use of a principles approach in sustainability projects and other collaborative endeavors.

\section{Project Context}

The project took place at Western Springs College (WSC), a co-educational state high school from a medium-high socio-economic area in Auckland, New Zealand's biggest city of 1.5 million people. It began in 2008 when the second author (a previous member of the school's governing board and current parent) suggested that WSC incorporate a sustainability policy into their strategic plan. The board agreed, and endorsed a goal "to work towards environmentally sustainable practices in all areas of school life" (Havill, 2008, p. 19). To implement the goal, they set up a sustainability panel, comprised of the Deputy Principal, two senior students who had been elected as 2008 environmental leaders by staff, a parent representative from the board, and representatives from three city council agencies with expertise in sustainable schools. The second author was invited to be the coordinator of the panel. The school agreed that under her supervision, graduate community psychology students would be brought into WSC to help drive and measure progress towards the sustainability goal. The project was approved by the University of Auckland Human Participants' Ethics Committee.

The project used an action research approach (Bradbury \& Reason, 2007; Lewin, 1946). Fittingly, action research aims to start where people are, and continually evolves as participants study, reframe and reconstruct social practices together (Kemmis \& Wilkinson, 1998). As noted by Davis (2007), this makes it particularly appropriate for messy, real world problems like promoting environmental sustainability. We drew especially on the philosophy of participatory action research (PAR) which emphasizes the central role of community members in setting the project goals and directing the research agenda (Park, 2006). PAR ensures that the project is focused on issues salient to the community under study (Suarez-Balcazar, Harper, \& Lewis, 2005) and encourages greater ownership of project outcomes by local people because they have had the chance to participate in decision-making (Allen, Kilvington, \& Horn, 2002).

We recognized from the beginning that we would benefit from a clear set of principles to guide our actions and decisions within the project. We understood that while collaborative projects can facilitate deep-level change (Jones, Yonezawa, Ballesteros, \& Mehan, 2002) there can also be conflict due to differences in the underlying philosophy and goals of the partners (Bartholomewa \& Sandholtz, 2009; B. Davies, Edwards, Gannon, \& Laws, 2007) as well as more mundane issues, such as resentment about the amount of work contributed by each party (Sandlin \& Feigen, 1995). We wanted principles that allowed us to maintain our integrity and 
purpose, no matter how the school responded. We therefore investigated literature from community psychology, action research, university-community collaborations and environmental psychology in order to settle on the principles we thought most likely to enhance our relationship with the school and allow the project to gain momentum. After a number of discussions, we decided on five: strengths-based, empowerment, role modeling, communication, and measurement and feedback. We now elaborate on the theoretical basis and our practical interpretation of each principle.

A strengths-based approach builds on capacities that participants or settings already possess (Lietz, 2004). According to Saleebey (2000), this approach is a paradigm shift; a movement away from society's and psychology's tendency to be fixated on problems and pathology. Whereas lamenting what is lacking can lead to downward spirals of blame and negativity, building on strengths may generate upward spirals toward optimal functioning (Daly \& Chrispeels, 2005; Fredrickson, 2003; Tschannen-Moran \& Tschannen-Moran, 2011). In the community development literature, the strengths-based approach has been described as a "powerful and transformative force for positive social change" (Linley, Bhaduri, Sharma, \& Govindji, 2011, p. 153). By seeking, celebrating, and building upon the strengths of the individuals, groups and wider networks that make up a community, it is possible to unearth people's intrinsic motivation for change, and in doing so inspire them to believe in their own potential and capacities (Linley et al., 2011).

A strengths-based approach compels practitioners to treat people as independent and capable, rather than as requiring experts to make decisions for them (Rappaport, 1981) and to take the humble stance that we cannot know the upper limits of a person's capacity to transform (Saleebey, 2000). Extending this notion to a broader ecological level, a strengths-based approach has high expectations of organizations, and envisages them to have many avenues for positive development. Importantly too, we reasoned that interventions based on strengths are more likely to be embraced by the organization as they go with, rather than against, established cultural values and practices (see Hemmelgarn, Glisson, \& James, 2006; Klesges, Estabrooks, Dzewaltowski, Bull, \& Glasgow, 2005). To implement this principle, we aimed to seek out and work with the people of WSC who already wanted to contribute to sustainability, and to celebrate and utilize their strengths and community connections. We also aimed to build project activities around pre-existing strengths within the culture of the school.

According to Rappaport (1981) empowerment is "the process by which people, organizations and communities gain mastery over their lives" (p. 3). It is consistent with action research philosophy and the strengths perspective because it focuses on helping people to discover and make use of the resources and tools within their reach (Saleebey, 1996). In particular, empowerment involves developing a critical awareness of the socio-political environment (Zimmerman, 1995) and discovering how to influence that environment.

By definition, an empowerment approach involves a considerable amount of restraint from researchers, so others can seize power (Labonte, 1994). When a research team is working with young people, it is important to balance support-giving with opportunities for them to take charge (see Cargo, Grams, Ottoson, Ward, \& Green, 2003; Jennings, Parra-Medina, Messias, \& McLoughlin, 2006; Larson \& Angus, 2011; Larson, Walker, \& Pearce, 2005; Wong, Zimmerman, \& Parker, 2010). In Wong and colleagues' (2010) study on typologies of youth participation and empowerment, the authors noted that the co-learning approach of action research encourages 
a balance of power between young people and adult researchers. Rather than being experts, adults can serve as sources of support, social capital, and positive reinforcement for youth partners. Through joint planning and decision-making, adults may gain access to youth perspectives while youth reap positive developmental benefits such as increases in competence, self-efficacy and sense of control (Zimmerman, 1995).

Because empowerment is a multi-dimensional construct, Hawe (1994) argued that in the context of community programmes it must be broken down into more practical and recognizable terms. In our project we were especially interested in the attitudinal dimensions of empowerment, such as political self-efficacy (Craig \& Maggiotto, 1982) and the skill dimensions of empowerment, such as how to advocate, lobby decision-makers, and take action (Balcazar, Seekins, Fawcett, \& Hopkins, 1990). In order to encourage empowerment, we aimed to help the people of WSC achieve change, not to impose our ideas for change on them. We also hoped the young people involved in the project would learn something about the political process of effecting positive sustainability changes.

Role modeling was perceived to have two key benefits. One is that people learn by observing others (Bandura, 1977). Several studies in environmental psychology show how people copy what they see or believe to be normal in a particular situation, such as littering (Cialdini, Reno, \& Kallgren, 1990), composting (Sussman \& Gifford, 2011), curbside recycling (Schultz, 1998), energy-use (Schultz, Nolan, Cialdini, Goldstein, \& Griskevicius, 2007) and towel re-use (Goldstein, Cialdini, \& Griskevicius, 2008). Therefore, we reasoned, if we model a sustainable behavior, that behavior has a better chance of being imitated by others and absorbed into the culture of the school (see Harré, 2011, for more on how modeling can be put to work for sustainability). When working with young people modeling may be particularly pertinent, since the period of youth involves the consolidation of lifestyle habits and behavioral patterns (Hurrelmann \& Raithel, 2005; Moreno et al., 2008).

The second key benefit is that engaging in the behaviours you are advocating is critical for integrity and credibility. In their paper on "greening" universities, Carmichael and Chameau (1999) argued: "In order to advance our thinking-and our behavior-towards more sustainable practices, we need to experience them ourselves. Nothing kills a movement like hypocrisy among its leaders; students and faculty know this, and so do our partners in the community" (p. 1). It is interesting that this principle has not featured strongly in community psychology and health promotion literature (although see e.g. Rush, Kee, \& Rice, 2005, for a study about nurses as role models). Possibly it is taken for granted. When working on a sustainability project, however, the practices being advocated take special effort as they penetrate almost every aspect of social life (see Woodhill \& Röling, 1998). In other words, there are myriad areas in which one can "be the change" and demonstrate more eco-friendly ways of doing things (e.g. through how one travels, what one purchases, how one uses energy or deals with waste). To meet this principle we aimed to "walk the talk", always considering the sustainability of our actions and image.

Effective communication has been consistently described as critical to collaborative partnerships (Bulloug \& Kauchak, 1997; Giesecke, 2012; Mattessich \& Monsey, 1992; Peel, Peel, \& Baker, 2002; Suarez-Balcazar et al., 2004; Suarez-Balcazar et al., 2005). For instance, in Peel and colleagues' (2002) review of practices influencing school-university partnership viability, "open communication that allows for frequent monitoring and decision-making based on the input of 
others" was identified as an effective practice, while "lack of communication" was identified as an ineffective practice (p. 322). The authors also attributed the successful outcomes of their own partnership to a collaborative spirit that was established early on through open and shared dialogue. In addition to formal channels, non-formal personal connections and communication links are posited to enhance the success of collaborative projects (Mattessich \& Monsey, 1992). Suarez-Balcazar and colleagues (2005) noted that establishing adequate communication requires time, respect for diversity, a grasp on the culture of the organization, good listening skills and commitment to the project. They also stressed the importance of discovering each other's preferred method of contact. While the literature emphasizes face-to-face interactions as the most effective (Berkowitz, 2000; Buys \& Bursnall, 2007; Stewart \& Alrutz, 2012), preferences may vary according to ecological factors such as ethnicity, age, technology, and geographic location (Suarez-Balcazar et al., 2005). Since youth are increasingly using etechnology to create and maintain social networks (Flicker et al., 2004; Lenhart, Purcell, Smith, \& Zickuhr, 2012) and to promote activism (Lombardo, Zakus, \& Skinner, 2002) it is important to understand these mediums in collaborative work with young people (see Davies \& Cranston, 2008; Flicker et al., 2008). Thus we aimed to establish and maintain excellent lines of communication with the school, via a variety of means tailored to the recipient.

Our final principle, measurement and feedback, emphasizes gathering data around an issue and feeding the information back to the organization for use. Through these activities, researchers can help identify the need for change and possible routes for achieving that change (Dickens \& Watkins, 1999). Then, after a course of action is completed, targeted data collection may be undertaken to evaluate its impact (Hockley \& Froggatt, 2006). Alongside conventional data collection (e.g. surveys), photography may be useful for documenting the journey of a collaborative project and the changes that arise from it (Kelly, 2005). Although this principle has two parts, we see them as inextricably linked within the action research spiral of planning, acting, observing and reflecting (Kemmis \& McTaggart, 1988).

Within traditional research frameworks, the dissemination of data to the community involved is often neglected or poorly executed (Montoya \& Kent, 2011). This is not only ethically problematic, but can lead to community members distrusting researchers (see Barnett, Anderson, Houle, Higginbotham, \& Gatling, 2010) and the research process itself (Montoya \& Kent, 2011). Since "knowledge is power" and can inform decisions that benefit the whole community (Israel, Schulz, Parker, \& Becker, 1998, p. 181) it is vitally important to disseminate research findings and interpretations to community members in a manner that is respectful, understandable and timely (Israel et al., 1998; Montoya \& Kent, 2011). In order to be consistent with the principle of measurement and feedback, we aimed to document the project's activities and measure their impact on the school community. We also aimed to give feedback on this to the school and to share our insights with external parties such as the local council and readers of this article.

\section{The Project in 2008 and 2009}

In 2008, our research team focused primarily on gathering baseline data and establishing relationships with members of the sustainability panel. We conducted a survey of the whole school using a questionnaire (see Sharma, 2009) and focus groups to get a sense of WSC's understanding of, and interest in sustainability, and found strong endorsement of the 
sustainability goal. We disseminated the results through several channels including discussions at the sustainability panel, an oral presentation to the staff, assemblies, workshops with a junior mathematics extension class, and a poster distributed to all classrooms. We worked hard to build relationships with the student environmental leaders appointed by the school by inviting them out to coffee and university talks, helping the environmental group run an "Ecoweek" and planting trees with them at a local reserve.

In 2009, the project intensified. The school appointed three environmental leaders who were enthusiastic, well connected and keen to work with us. The primary focus of the year was on the design, building, painting, installation and promotion of new waste stations that would allow the school to separate waste into landfill, recycling and compost. The environmental leaders chose this focus, as they thought an artistic project would be appealing to WSC students and the school had previously done some work towards waste management. Our research team assisted the leaders and their support teacher in coordinating all the tasks needed to get the waste stations in place. We also helped them run extracurricular events such as an after school waste audit, a painting bee to paint murals on the waste stations and a lunchtime expo that showcased them. We held several meetings throughout the year to help them plan these events.

In June, we made a short film with the leaders called Gumby the Fairy and his Merry Band of Eco Pixies in the Quest for Sustainability (Gumby) to inform the school community of the waste station project and recruit helpers (see: www.youtube.com/user/gogreenwithgumby). Two of the environmental leaders and the support teacher acted in the film, while the third leader assisted the university crew. Gumby was screened in a full school assembly and students were subsequently invited to participate in two media workshops. These workshops were organized and facilitated by the research team and attended by 31 students. They included a demonstration waste audit, viewing and discussing video clips about recycling and environmental protection, and taking creative photographs of waste for a competition. Students also mapped out prospective locations for the waste stations.

In October, Author One led the production of a music video called Sort It Out to launch the waste stations and educate people as to how to use them (see our YouTube page). The music video involved 27 students in singing, dancing, acting and costume design, and was screened in school assemblies. In December, we held a Showcase of Sustainability community evening with the environmental leaders to celebrate our combined efforts. The showcase included screenings of Gumby and Sort it Out, slideshows of photographs and documentary footage from the media workshops and waste station painting bee, and shared the results from several surveys and audits conducted throughout the year. In addition to the leaders, 89 students (10\% of WSC) were involved in at least one of the above projects. Even more students were peripherally involved. For example, two English classes were shown the photographs taken in the media workshops and invited to submit captions for a competition.

It is of note that in 2010 , the school introduced an ambitious goal to reduce landfill waste by $50 \%$, increased the sustainability student leadership team to nine students, and substantially increased the status and time available to the support teacher. In 2011, they received a substantial waste management grant personally presented by New Zealand's Minister for the Environment. By the end of 2012 the school had a state-of-the-art waste management system and had reduced the compostable waste going to landfill by $85 \%$ and recyclable waste going to 
landfill by $68 \%$ (Kilian \& Yates, 2013). While we cannot claim this is all a result of our project, we believe our research team's approach to working with the school is likely to have contributed to sustainability values getting increasing traction.

As noted, the overall aim of this study was to shed light on how principles may be used by researchers and community practitioners to guide their practice within collaborative projects. Using our sustainability project at WSC as an example, we present analysis of and reflection on our five guiding principles. We explore three key questions: (1) How did we experience our guiding principles? (2) What can we learn from the school's experience of our practice? (3) In what ways did our principles complement and conflict with each other? Our analysis culminates in key insights we gained from the reflective process and associated recommendations for others.

\section{Method}

This study was informed by phenomenological inquiry. This involves collecting data from people who have experienced a particular phenomenon, and then attempting to uncover the essence of their experience (Brown \& Duke, 2005). It also drew on autoethnography, a method in which researchers use their own experience to investigate the phenomenon under study, sometimes in combination with data from others (Chang, 2008). While autoethnography is most often conducted by single researchers, collective approaches that allow for multiple voices to be heard are becoming more common (see Belgrave, Celaya, Gurses, Boutwell, \& Fernandez, 2012; Phillips, Harris, \& Larson, 2009). As our guiding principles were the phenomenon of interest, each research team member completed a self-reflective survey. We also wished to understand how the principles were experienced by those partly outside the experience, but affected by it - that is, key participants from WSC. This is in keeping with the principle of triangulation that suggests a picture can be built up from multiple informants (Chang, 2008; Healy \& Perry, 2000). To this end interviews were conducted with selected members of the school.

\section{Research Team Self-Reflections}

Our research team consisted of Author two, 48 years old (all ages are as of 2009), an associate professor in the School of Psychology at The University of Auckland; Author one, 23, who was involved as an honors student (first year postgraduate) in psychology in 2008 and a doctoral student in 2009; Author three, 25, a masters student in psychology on the project in 2008; Author four, 24, an honors student in psychology in 2008; Author five, 22, honors student in psychology in 2009 and Author six, 24, a student completing a postgraduate diploma in environmental management in 2009.

Each team member's contribution to the project was influenced by their research interests and academic requirements. As already noted, Author two was coordinator of the sustainability panel as well as the academic supervisor of the team. Author one coordinated the 2009 film productions and organized the media workshops with Authors six and two. Author three led the development and execution of the questionnaire in 2008, with Authors four, two and one 
assisting with various related tasks. Author five explored the impact of the project on the environmental leaders and their social networks, while Author six focused on understanding WSC's waste systems and littering habits.

To provide self-reflections, we needed a method that allowed us to focus on each principle separately, and then examine the complex interplay of the principles in action. Therefore we each independently completed a two-part survey, designed by Authors one and two and administered via email. The first section asked what we had done to meet each principle, what had helped us, and what had hindered us. The second part asked which principles worked well together and why, and which principles came into conflict with one another and why. We each wrote between six and twelve pages of reflections.

\section{School Participant Interviews}

Participants were the three environmental leaders from 2009 and four teachers from the sustainability panel, selected purposely as we wanted the perspectives of school personnel we had collaborated with most closely. They were interviewed by a graduate student who was not part of the research team in the hope that participants would provide more candid perspectives (see Chang, 2008). Interviewees were provided with verbal and written information about the research process and allowed to ask questions before signing their consent. The interviews began with a broad question (what are the first five things that come to mind when you think of the sustainability research team?) and then targeted participants' perspectives in relation to each of our principles (see Appendix 1). Participants were also asked about their role in the broader sustainability project. Interviews were audio recorded and lasted between 20 and 40 minutes, with 10-15 minutes typically spent on the target questions. Participants were sent their transcripts and given the opportunity to comment and request changes, however, none did so.

\section{Data Analysis}

Data analysis procedures were guided by the Stevick-Colaizzi-Keen method, as described in Brown and Duke's (2005) collaborative phenomenological self-study. This reductive method is used to "systematically distill essential themes, ideas, and concepts from dense, or "thick," textual descriptions" (Duke, 2008, p. 24). The ultimate aim of the phenomenologist is to produce a concise, yet vivid written summary that depicts the "essence" of the phenomenon in question (Creswell, 1998). To this end, Author one began by reading through the material pertaining to each principle multiple times, identifying and highlighting significant statements and noting down her initial ideas for common themes. Author two then examined the dataset and Author one's notes, and made comments and further suggestions. Next, Author one went through the dataset again and grouped similar statements together into clusters of common themes. For each principle she constructed two tables, one for common themes and significant statements originating from the research team and another for themes and statements from the school interviewees. She also constructed a diagram to show which pairs of principles the research team had identified as complementary and which pairs we had identified as potentially conflicting. Author two then examined the tables against the dataset to verify and further develop the analyses. 
Next, Author one began to work the material in the tables into written summaries to convey the essence of how each principle was experienced by our research team and perceived in our practice by the school. The material we provided about how the principles worked together or conflicted was also summarized. As articulated by Thomas Duke (Brown \& Duke, 2005) phenomenological inquiry is "an intensely creative and dynamic process, in which ideas are generated, analyzed, reorganized, recycled, and transformed" (p. 181). Writing and rewriting is considered a critical part of the method (van Manen, 1990), as it is through this process that researchers can distill meanings (Starks \& Trinidad, 2007). The two lead authors worked on several iterations of the results, experimenting with different structures and formats. There were no obvious disagreements between the lead authors during analysis. Once they were satisfied, Authors three, four, five and six were asked to check that the summaries were true to their experience and to suggest any alterations. However, no suggestions were made and all team members indicated they were satisfied with the interpretation of the survey data.

A notable limitation of this study was that we did not ask the school participants to comment on our interpretation of their data. We had reasons for this, however. First, we were concerned about exhausting the school with contact. Second, the format of our results meant that the schools interviewees' perspectives were summarized in tandem with our research team's honest and occasionally negative appraisals of the project. We felt that sharing these could be potentially detrimental to our relationship. Thus, we recognize that what is presented below is first and foremost our research team's account. Furthermore it potentially favors the perspectives of the two lead authors, who spent comparatively more time working with the school than did the rest of the research team and who lead the analysis and interpretation. To enhance trustworthiness, quotations from participants in both groups are frequently incorporated (Healy \& Perry, 2000). School participants are referred to by their role to protect confidentiality.

\section{Summary of Each Guiding Principle}

\section{Strengths-based}

One theme that emerged from the research team's reflections was that the project had built on the school's strength in the arts, which we also described as key to WSC's culture and identity. All school participants also recognized this in their interviews, for example: "I think using the art and also the media thing worked really well, it just drew in not just people interested in sustainability but people who were interested in art, especially since that sort of stuff is quite big in our school" (student leader). In a broader sense too, some participants from both groups indicated that film and photography are particularly thriving fields of artist expression in our contemporary, technological cultures and young people are drawn to these mediums. One teacher said that the Gumby film had "galvanized" the WSC community, and had "absolutely" grabbed the attention of staff and students.

A second aspect of our strengths-based approach noted by some of the research team was that we worked from the entry point of the student leadership system. There was also evidence of some school participants recognizing this, for example: "What I've seen is a hard core group that worked really closely with the leaders, so yeah, I think they've done well with that" (teacher). Multiple strengths of the 2009 environmental leaders came through in our research 
team's reflections, with our use of terms such as "enthusiastic", "knowledgeable about the school's culture" and "highly socially connected". We noted how we had encouraged them to draw on their networks, and a social network analysis conducted by Author five (see Douglas, 2009) indicated that many of the attendees at the events were directly linked to the leaders.

Finally, a theme from the research team was that we had utilized the school's strength as a community that is open to new ideas and willing to try them. This meant that WSC was amenable to collaborating with our team and exploring how sustainability could be promoted in a high school context. A few school interviewees spoke proudly about WSC's progressive identity. For example, one teacher said: "I think that WSC is ... used to beating a path that's different from other schools ... I'm sure it's within the culture of the school to be able to say we can make this work ... we're doing this because we believe in creating a better pattern for the future".

\section{Empowerment}

One theme produced by the research team was that we tried to create an empowering atmosphere for the environmental leaders. First, we encouraged them to come up with their own ideas for sustainability solutions and worked on projects they suggested. Second, we helped them plan how they would take action, by working together to assign tasks with time frames and encouraging and supporting them to approach people who had the power to make things happen. Third, we gave them opportunities to take charge but made ourselves available to assist if needed.

Another theme that emerged was that through our scaffolding, the leaders improved their organizational skills. For example, Author five contrasted the poor turnout of the leaders' environment group meeting in March (6 students) with the waste audit in July, when they successfully recruited 15 volunteers to sift through rubbish for two hours after school. It is of note that between these events we had discussed with the leaders strategies to attract students to the project, such as asking peers for support and marketing events as a chance to socialize while giving back to the community.

Although there was consensus we were focused on, or even "obsessed" (Author two) with trying to empower the student leaders, some of our team expressed concerns that we had failed in this regard. This was apparent in our descriptions that two of the leaders appeared to be gradually losing interest as the waste station project progressed. Author six recalled an afternoon when she and Author one had arranged to help them paint anti-graffiti varnish on the waste stations and only one leader had turned up: "I think we took too much responsibility for them and they began to think it was all right for us to do that and for them to step back". Author two reported struggling with a sense that we were trying to empower people to do things they were "not bursting at the seams to do". She also questioned the notion that one can empower another: "How do you empower people - don't they have to seize power for themselves?" Author one reflected that she might have imposed a filmmaking agenda on WSC. It is notable that the language we used to describe ourselves in relation to this principle also hints at the tension we recognized and were constantly trying to balance. That is, we wanted the leaders to become "empowered" but to do this we felt we had to be fairly directive by "encouraging them to come up with ideas", helping them plan, and even "giving them opportunities" as if we were ultimately in charge. 
In spite of our worries, the school participants made many comments that suggested they observed or experienced us as empowering. The support teacher whom we worked with most closely said, "They did a good job not to sort of say 'look you should be doing this and you should be doing that' because when you start doing that the kids will rebel". He also described us as accepting of where people were at and having an "every little bit counts" ethic towards sustainability. Finally, he commented that the waste station project had attracted "a lot of buyin" from students and "when you have that buy-in the ownership for them to actually use it and contribute goes up".

One student leader stated: "They took our ideas and used those and then used their kind of abilities and their help and stuff to put those forward and still achieve something bigger". Another leader said the research team steered her in the right direction when she got lost, and "made opportunities more available to students". All three leaders expressed pride in what they had achieved, and two of them mentioned that they had done more than the students leaders with other portfolios: "the cultural leaders and the academic leaders have done, you know, 'math's week' and 'cultural week' but that happens every year ... I think we've actually done more this year because we've done new projects ... original projects". One teacher reflected that through the project the leaders had acquired "generic skills that they can apply to any other situation that they want to be active around".

\section{Role Modeling}

Our research team described numerous behaviours we tried to model in our visits to WSC. In terms of transport, we made an effort to walk, cycle, or catch a bus to the school. We usually provided food at meetings or events and made sure it met at least some of these sustainability principles: organic, fair trade, locally grown, low packaging. To ensure this we often brought in baking or food from our own gardens. We strived to minimize waste and dispose of it mindfully, even if this meant taking it home. Finally, we gave out relatively sustainable prizes to competition winners, such as cinema vouchers or reusable lunchboxes.

Most of the school participants perceived our role modeling to be salient, with one environmental leader saying it was "insanely" noticeable. Two teachers talked at length about how it had influenced them to think critically about their own habits. Walking the talk was described by one teacher as "absolutely" integral to the project's authenticity and "another way of thrusting it forward". Interestingly, the environmental leaders seemed to include themselves in the role modeling when they were asked about particular behaviors they had noticed. For example, although the research team provided all the food at events, one leader said: "just like you know, we often have food, but try to buy things without packaging or recycling packaging or not driving to places or, yeah". Another recalled that "everyone" made a conscious effort not to leave rubbish lying around, and that it was important to all set a good example, because "no one wants to contradict themselves". These comments suggest that the leaders identified waste conscious behaviors as group norms and clearly grasped the implications that hypocrisy would have on our combined team's credibility.

A notable theme in our research team's reflections was that we had all experienced practical difficulties with role modeling. For instance, while two of us lived near the school and found it easy to walk or cycle, others lived a considerable distance away and often opted to drive. Many of us expressed frustration that role modeling requires extra time and effort and "a rejection of 
convenience culture" (Author one). As Author five wrote: "It's easier to buy packaged biscuits than to make them yourself, it's easier to drive than to take the bus". Nevertheless, we generally experienced modeling as rewarding because it aligned with our values and therefore felt good. A few of us described how we had found solace and inspiration in each other. Experiencing the same challenges built our team spirit, and if we ever made an "eco-blunder" (Author one) we could confide in each other and receive the empathetic reaction we needed to persevere.

\section{Communication}

Our research team reflected that we communicated with members of the school through multiple modes, including email, text messages, meetings, phone calls, and a Facebook account Author one set up. When exchanging personal details we also asked people for their preferred mode of contact, and tailored our communication accordingly. Some of us emphasized how vigilant we had been in ensuring our outgoing messages were crystal clear. Author two wrote: "We NEVER forwarded emails complete with old headers, tons of irrelevant information and quick, badly written messages".

A strong theme that came through in our reflections was that our "technology savvyness" and "understanding of youth mediums"enabled us to communicate effectively with the young people involved in the project. Facebook, for instance, proved to be a "fail-safe" (Author one) way to get hold of students, as well as a forum for publicizing waste station events. The environmental leaders strongly endorsed the use of Facebook too. For example: "The Facebook thing did really well. I think that really drew people in, anyone that came to one event was constantly getting reminded [about other events]... even if they didn't come, like kind of kept it on their minds".

Participants from both groups recognized that communication problems within the project stemmed primarily from the school end. Several research team members recalled feeling angst over nagging people when they had agreed to do something by a specific date but had not done so, or had not responded when we had asked them something important, such as whether a meeting was going ahead or not. Many school participants indicated sympathy for the challenges we faced. For example: "I'm sure they would wish that the school was more responsive. At times we get so busy that we don't respond, and we sort of prioritize things and sometimes that gets down the priority list a little bit. I've always felt guilty about that" (teacher). Another staff member said she admired our persistence and energy and thought it must be very frustrating for us. All teachers expressed concerns about the school's internal communication, in that not enough staff were informed about the project or involved in it. They also identified a need for staff with reduced workloads or paid management units that would allow more time for sustainability initiatives.

\section{Measurement and Feedback}

In our reflections we recalled various ways in which we measured the impact of the project and the efficacy of interventions and activities. These included questionnaires, audits, focus groups, social network maps, interviews, quizzes, feedback forms and general record keeping. We also identified multiple modes in which we fed results back to the school. These included posters 
put up in classrooms, presentations to the sustainability panel (in person or via email), presentations at full school assemblies, and our sustainability showcase evening. As coordinator of the panel, Author two also wrote up concise meeting minutes and annual reports on the school's sustainability progress to circulate to panel members and the principal.

Many of our research team expressed gratitude that the school was highly receptive to our measurement. We described teachers as "flexible" and "accommodating" when we conducted measures in the classroom, and noted that senior students had willingly assisted us with the administration of questionnaires when asked. Those of us involved in 2008 commended our measurement and feedback efforts in that year, especially our execution of the whole-school questionnaire. Those of us involved in 2009, however, expressed concerns about our measurement. Author two reflected that we had been very wary of "over measuring" or "intruding" on WSC, which may have led us to bypass some important measurement opportunities. We reported struggling with evaluating the impact of our films and admitted that we were not always completely clear on what we were measuring and why. Some of our team also acknowledged that we could have disseminated findings more thoroughly, especially the results of the waste audit. Competing demands on our time and getting wholly engrossed in the practical side of the project were reasons we gave for not utilizing all the available channels for sharing the information. In hindsight, many of us described dissemination as something we would have liked to do much better.

Not surprisingly, the school participants indicated only vague awareness of our measurement and feedback. One teacher recalled that we had conducted surveys and audits and were trying to measure the success of our films, but was only aware of this because she had attended a sustainability panel meeting. Our research agenda was not salient to the environmental leaders either. When asked if she was aware of our measurement, one said: "Well kind of, I know she [Author one] is doing a project but I don't really know the findings, I don't mind, it's not, but yeah I don't really know like her thesis or anything like that". Importantly, participants from both groups acknowledged that we had presented at assemblies a number of times in 2009. However, these presentations were not for the purpose of sharing official research findings, but for showing films, artwork and photos and publicizing what was happening next.

\section{Complementary and Conflicting Principles}

As noted the research team also reflected on which principles we felt worked well together and which we felt conflicted with each other, at least to some degree. Figure 1 shows the pairs of principles we identified in the survey as complementary to one another (solid lines) and the pairs we identified as at least partially conflicting (dotted lines). We elaborate on these relationships below. 


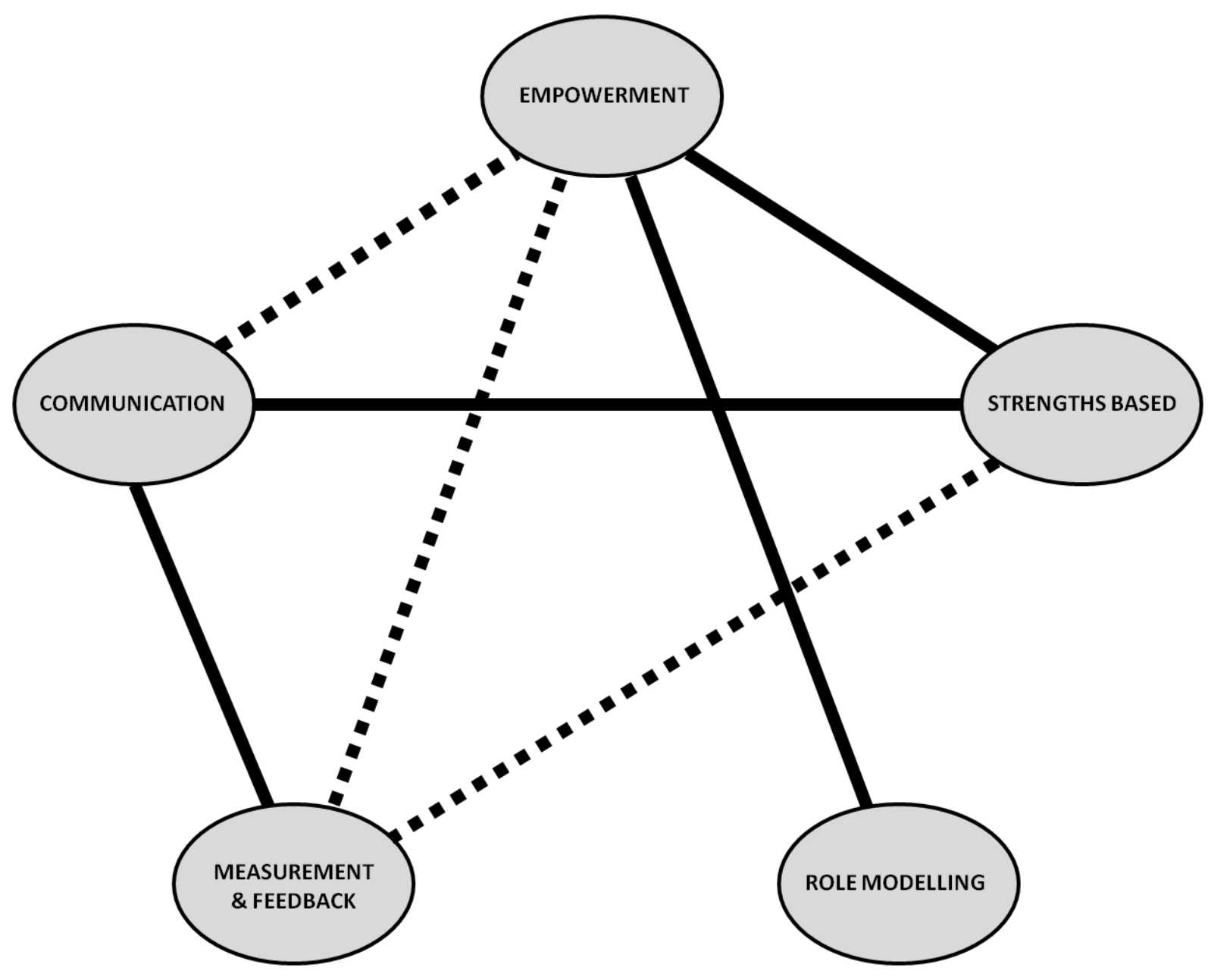

Figure 1. Complementary principles (solid lines) and potentially conflicting principles (dotted lines) described in the research team survey.

\section{Complementary Principles}

Communication and a strengths-based approach were considered complementary, as asking the right questions (good communication) can lead to the discovery of individual and community strengths. Then, working on projects identified by a strengths-based approach can increase rapport and, in turn, lines of communication. For example, Author one noted that after the 2009 research team and student leaders spent a Sunday working together on the Gumby film, we became a much more cohesive group and communication between us improved markedly. In addition, we noted how working with the communication strengths of the participants was particularly effective. Regular meetings, texting and Facebook were especially good ways to communicate, email was not.

Communication and measurement and feedback were also highly complementary. As Author five noted: "Measurement and feedback also work well with the communication principle. Reporting results from, say, a waste audit, is a more powerful communication than just saying 
that we think waste disposal needs attention". Author four articulated that good communication is a prerequisite for accurate measurement and effective feedback. Both should be culturally appropriate and use language participants can relate to, or they will not be treated as relevant, resulting in poor data (compromising measurement) and low uptake (compromising the utility of feedback).

We considered the strengths-based and empowerment principles to be fundamentally interrelated, that the empowerment of a person was contingent on them perceiving that their assets had made a positive contribution to the project. As Author four wrote: "If you are utilizing a person's strengths they are going to feel a greater sense of mastery over what they are doing than if they are doing a task they don't feel competent in". In the case of WSC, this occurred most obviously for one of the 2009 environmental leaders who was particularly skilled in photography and design. She submitted several photos as part of the media workshops, sketched designs for the waste stations, liaised with the school carpenter to get them built, and created a page for a community bulletin that showcased all our projects. Author one reflected that this leader's sound commitment to the project was probably partially due to its compatibility with her strengths and the resulting positive reinforcement she received.

Role modeling and empowerment were considered complementary, as being exposed to our eco-friendly behaviors could lead students to see them as easier to enact. This may be particularly true given the similar age of the university students to WSC students. Author five wrote about how role modeling aligned with empowerment because of its authenticity: "It doesn't involve directly imposing ideas or standards on people, it's more about just being authentic in our message, and people can learn from that without us preaching at them".

\section{Principles With Some Degree Of Conflict}

Measurement and feedback and empowerment were noted by three of us as in tension with each other. As Author six wrote: "Measurement and feedback are messy processes and hinder the broader principles of empowerment and strengths-based. They call for detail, while the latter call for big picture, and being willing to work. So this principle may constrict other ones". On the other hand, she reasoned that measurement and feedback are necessary for the longterm empowerment of an organization: "If the school has data they can use it to advocate for more change and can concretely see how far they've come. If we leave without feeding back the information we've collected, new people will have nothing to work from and will find it harder to campaign for changes. So while it's constricting in the short-term, it's essential to keep the project going".

Author one articulated that the way to overcome the tension between these two principles is to get community members actively involved in devising research questions and collecting data: "that way they'd probably feel much more empowered to do something constructive with the results". We know from our experiences at WSC that involving staff and students in research tasks is difficult, and creates additional logistical challenges. We generally got the impression that they were content with us conducting measurement on the school but were not particularly interested in participating in the research design, data collection, analysis or dissemination. In a broader sense, Author two expressed that empowerment represented the "essence" of the school and measurement represented the "essence" of the university: "To truly 'empower' we 
would have had to have let go of our agenda, but we couldn't do that. To truly 'measure' we would have had to have ignored the school's needs and just gone ahead and gathered the data we wanted". This comment reflected a deeper conflict between our aspirations to meet the ideals of action research and the pressure we felt to rigorously monitor changes in the school population for our theses and dissertations. In hindsight, however, the most compelling evidence for change was not in the waste audits, formal surveys or observations we had done (or not done) but in the cultural and physical artifacts we had co-created with the school (films, photographs, waste stations), and most significantly, in the new student leadership structure and ambitious waste reduction target described in the introduction. So, paradoxically, dedicating ourselves to the action-related principles may have resulted in more robust outcomes.

A further tension was noted between communication and empowerment. We wanted the school to go "full speed ahead" towards sustainability. If we had been absolutely honest in our communication we would have fully expressed our ideas and values. However, for the sake of empowerment, we tried to keep our vision in check. This was sometimes difficult. For example, Author one recalled how in a planning meeting for the waste stations, we had not been able to resist pushing for a compartment for compostable food scraps, despite disinterest on the part of the environment leaders. After the meeting we had felt concerned that we had been "too honest" and compromised our empowerment aim of helping people achieve change, but not imposing our ideas on them. On the other hand, we knew this was a cutting edge improvement that would better position the school to gain external support, and thus be empowering to the organization as a whole.

\section{Discussion and Recommendations}

This study enabled our research team to critically reflect on our practice through the framework of five guiding principles. By gathering the perspectives of school community members, we were able to glean deeper insights into how these principles operated and how we could improve our practice. While the project was successful in the sense that the school went on to take full ownership of their sustainability goal, we do not claim to have uncovered an objective truth about the utility of these principles.

First, we cannot know exactly what role our research team played in the project's success. It is possible that the school's increasing interest in sustainability was part of a general societal trend and would have developed with or without our research team's intervention. Second, we recognize that the findings presented here are limited by the shortcomings inherent to selfreflection, including memory distortion and other self-serving biases. Third, although the graduate student who conducted the interviews was not affiliated with the project, it is important to acknowledge that interviewees may not have been as candid as we had hoped for because they were aware we would see their responses.

Finally, the second author had multiple roles within the school, as a parent, a former member of the governing board, the school's sustainability panel coordinator and a researcher. These factors amongst others combine to give this, like all case studies, unique characteristics. Despite these caveats, we offer recommendations for other researchers and community practitioners 
who may be interested in working to promote environmental sustainability, or who may find a similar principles-based approach useful in their own collaborative endeavors.

\section{Recommendation One}

As with any community development work, we recommend starting with the locally identified needs of the organization (Wolff, 2000) alongside their strengths. In the case of our project, several parties within the school, such as the board, the sustainability panel, and the student environmental leaders, identified waste and litter reduction as issues in need of attention. The school also had prior established links to a council agency with expertise in waste minimization and resources for waste auditing. Although waste is likely to be a relevant issue for most organizations, there are numerous other areas in which sustainability leadership can be demonstrated (e.g. examining consumption practices and switching to fair trade or more local suppliers, improving facilities for active transport, participating in challenges to raise money for charities such as Oxfam).

\section{Recommendation Two}

Consider choosing a set of guiding principles. Principles are useful in several ways. They can help with real-world decision making by providing a framework against which to weigh up different options. In conjunction with this, they can produce a more coherent team, as they provide boundaries for conversation. For example, we did not debate if we should role model what we were advocating, although we did debate how to do this in particular instances. Having the principles helped prevent us from sinking into an unguided chaos that may have damaged our relationships with each other and our sense of being a team.

The principles also meant we were less attached to specific end results than we might have otherwise been. In other words, we could judge the success of the project on the basis of our process rather than on the school's "progress". This detachment is critical to maintaining a genuinely collaborative partnership, as it allows a research team to remain open to dialogue about a project's direction. Paradoxically too, detachment may also enhance persistence in the face of setbacks, by taking the focus off outcomes as key indicators of success. Although we did not do this often enough, regularly reflecting as a team on how well you are living your guiding principles is likely to improve your ability to deal with the challenges of collaborative projects.

\section{Recommendation Three}

Expect that you may need to switch between different roles such as learner, facilitator, researcher, and advocate throughout the project (Connors \& Seifer, 2000). For example, we suspect it is almost impossible to be an effective empowerment practitioner and rigorous population-level researcher simultaneously, but you may be able to alternate between these roles. Deciding when to prioritize one stance over the other is rarely simple. For instance, do you "allow" community members to gather data in their own way (which may violate your ideas of rigor), or do you insist on controlling the process? There is no single answer to this question and we suggest that it is not always useful to struggle to be both completely true to the demands of your external affiliation and completely "collaborative" in relation to the same task. Similarly, it is important to genuinely learn, but also to teach when it is clear you have expertise that will help move the process forward. 


\section{Recommendation Four}

Role modeling the behavior you value is important. It shows integrity, an essential antecedent to trust and credibility (Simons, 2002). It also provides an avenue by which community members can experience and learn about the target issue. In the case of sustainability projects, there are numerous relevant behaviors. Targeting a few highly visible ones (e.g., bringing a reusable coffee cup to meetings; providing unpackaged food) and consistently sticking to them will reinforce the sustainability message and increase the chance that it will be adopted by others (Harré, 2011). In the case of collaborative projects focused on global social justice, using certified fair trade products would be an obvious and highly visible choice.

\section{Recommendation Five}

Consider collaborating with organizations that are located close to researchers' homes or workplace. In the case of sustainability projects, this will inevitably make role modeling easier, and may enhance your commitment to the project because of a shared place-identity with community members (see Harré, 2011). Prior personal connections between researchers and organizational staff are an asset to collaborative projects and may be critical in moving them beyond the initial stage (Buys \& Bursnall, 2007). Unless there is a history of conflict, it is likely that the more connections there are between the "external" team and the community, the more viable the project.

\section{Recommendation Six}

Take time out to plan measurement and adopt a wide lens in deciding what qualifies as a research artifact. Media and artwork created by community members, as well as new infrastructure, organizational policies, and recognition from external agencies are primary sources of evidence. These can be documented throughout the project by keeping a log of emails, meeting minutes, community newsletters, and so on. In addition to serving as records of events, photographs can powerfully capture changes to a community's environment over time and are essential for creating lively presentations about the project for sharing both internally and externally. Not measuring every aspect of the project and instead focusing on action may ultimately produce something of greater worth that is also easier to measure.

\section{Recommendation Seven}

Be patient. Be generous with offering your time and assistance to the community you are working with, especially in the early stages of a collaboration when personal contact is imperative to trust building (Suarez-Balcazar et al., 2005). In particular, it is important to volunteer to help with activities that have no obvious relationship to your agenda (see Barnett et al., 2010). This is part of adopting a long-range social change perspective (see Strand, Marullo, Cutforth, Stoecker, \& Donohue, 2003). Such a perspective accepts that you are not above the invisible and sometimes tedious work of simply doing what needs to be done. In this way too, your presence is assisting the community with their agenda, rather than overwhelming them with your own. 


\section{Future Research}

Future research could further investigate the utility of these principles in action research projects. Experimenting with different levels of role modeling may produce interesting insights about social influence and the transmission of desirable practices. The current study suggested that effective modeling involves not only demonstrating the behavior you hope to inspire, but also drawing attention to it without appearing to be judgmental. Moreover, it is important to choose the right behaviors to focus on. Behaviors that are visible and enhance group identity, like the choice of food at events, may be particularly powerful in prompting ownership of a project. Further studies could investigate people's reactions to researchers who model different types of behaviors, who demonstrate varying degrees of alignment between their words and deeds, and who draw attention to their own behavior using different strategies.

To conclude, we invite other action researchers to adopt our principles or principles that fit their setting and to reflect on how they are experienced and the tensions between them. Ongoing self-reflection may help maintain the research team's focus and provide useful data to further understand the principles' efficacy. This will enable us to build critical understanding about the guiding frameworks that can be used to inspire sustainability initiatives in community settings.

\section{Contact information:}

Niki Harré

School of Psychology, The University of Auckland,

Private Bag 92019

Auckland 1142, New Zealand

Email: n.harre@auckland.ac.nz

\section{References}

Allen, W., Kilvington, M., \& Horn, C. (2002). Using participatory and learning-based approaches for environmental management to help achieve constructive change. Wellington: Landcare Research Contract Report.

Balcazar, F. E., Seekins, T., Fawcett, S. B., \& Hopkins, B. L. (1990). Empowering people with physical disabilities through advocacy skills training. American Journal of Community Psychology, 18(2), 281-296. doi: http://dx.doi.org/10.1007/BF00931305

Bandura, A. (1977). Social learning theory. Oxford, England: Prentice-Hall. 
Barnett, M., Anderson, J., Houle, M., Higginbotham, T., \& Gatling, A. (2010). The process of trust building between university researchers and urban school personnel. Urban Education, 45(5), 630-660.

Bartholomewa, S. S., \& Sandholtz, J. H. (2009). Competing views of teaching in a schooluniversity partnership. Teaching and Teacher Education, 25(1), 155-165. doi: http://dx.doi.org/10.1016/j.tate.2008.07.001

Belgrave, L. L., Celaya, A., Gurses, S. A., Boutwell, A., \& Fernandez, A. (2012). Meaning of political controversy in the classroom: A dialogue across the podium. Symbolic Interaction, 35(1), 68-87.

Berkowitz, B. (2000). Community and neighborhood organization. In J. Rappaport \& E. Seidman (Eds.), Handbook of community psychology (pp. 331-357). New York: Plenum Press.

Bradbury, H., \& Reason, P. (2007). The SAGE handbook of action research: Participative inquiry and practice. Thousand Oaks, CA: Sage Publications.

Brown, J. D., \& Duke, T. S. (2005). Librarian and faculty collaborative instruction: A phenomenological self-study. Research Strategies, 20(3), 171-190.

Bulloug, R. V., \& Kauchak, D. (1997). Partnerships between higher education and secondary schools: Some problems. Journal of Education for Teaching, 23(3), 215-234.

Buys, N., \& Bursnall, S. (2007). Establishing university-community partnerships: Processes and benefits. Journal of Higher Education Policy and Management, 29(1), 73-86.

Cargo, M., Grams, G. D., Ottoson, J. M., Ward, P., \& Green, L. W. (2003). Empowerment as fostering positive youth development and citizenship. American Journal of Health Behavior, 27, 66-79.

Carmichael, C. S., \& Chameau, J. A. (1999). Avoiding the 'lesson of hypocrisy': The role of campus practice in education for sustainability. Paper presented at the Environmental Management for Sustainable Universities, The International Institute for Industrial Environmental Economics at Lund University, Lund, Sweden.

Chang, H. (2008). Autoethnography as method. Walnut Creek: Left Coast Press, Inc.

Cialdini, R. B., Reno, R. R., \& Kallgren, C. A. (1990). A focus theory of normative conduct: Recycling the concept of norms to reduce littering in public places. Journal of Personality and Social Psychology, 58(6), 1015-1026.

Connors, K., \& Seifer, S. (2000). Partnership perspectives (Vol. 1). San Francisco, CA: Community-Campus Partnerships for Health.

Craig, S. C., \& Maggiotto, M. A. (1982). Measuring political efficacy. Political Methodology, 85109. 
Creswell, J. W. (1998). Qualitative inquiry and research design: Choosing among five approaches. Thousand Oaks, CA: Sage Publications.

Daly, A. J., \& Chrispeels, J. (2005). From problem to possibility: Leadership for implementing and deepening the processes of effective schools. Journal for Effective Schools, 4(1), 725.

Davies, B., Edwards, J., Gannon, S., \& Laws, C. (2007). Neo-liberal subjectivities and the limits of social change in university-community partnerships. Asia-Pacific Journal of Teacher Education, 35(1), 27-40.

Davies, T., \& Cranston, P. (2008). Youth work and social networking. Leicester: National Youth Agency.

Davis, J. M. (2007). Rethinking the architecture: An action researcher's resolution to writing and presenting their thesis. Action Research, 5(2), 181-198. doi: $10.1177 / 1476750307077322$

Dickens, L., \& Watkins, K. (1999). Action research: Rethinking Lewin. Management Learning, $30(2), 127-140$.

Douglas, B. (2009). Socialising sustainability: The story of three environmental leaders. Honours dissertation, University of Auckland.

Duke, T. S. (2008). Hidden, invisible, marginalized, ignored: A critical review of the professional and empirical literature (or lack thereof) on gay and lesbian teachers in the United States. Journal of Gay \& Lesbian Issues in Education, 4(4), 19-38.

Flicker, S., Goldberg, E., Read, S., Veinot, T., McClelland, A., Saulnier, P., \& Skinner, H. (2004). HIV-Positive youth's perspectives on the Internet and eHealth. Journal of Medical Internet Research, 6(3).

Flicker, S., Maley, O., Ridgley, A., Biscope, S., Lombardo, C., \& Skinner, H. A. (2008). e-PAR: Using technology and participatory action research to engage youth in health promotion. Action Research, 6(3), 285-303.

Fredrickson, B. L. (2003). The value of positive emotions: The emerging science of positive psychology is coming to understand why it's good to feel good. American Scientist, 91(4), 330-335.

Giesecke, J. (2012). The value of partnerships: Building new partnerships for success. Journal of Library Administration, 52(1), 36-52. doi: 10.1080/01930826.2012.629964

Goldstein, N. J., Cialdini, R. B., \& Griskevicius, V. (2008). A room with a viewpoint: Using social norms to motivate environmental conservation in hotels. Journal of Consumer Research, 35(3), 472-482. doi: $10.1086 / 586910$ 
Harré, N. (2011). Psychology for a better world: Strategies to inspire sustainability. Auckland: Department of Psychology, University of Auckland.

Havill, K. (2008). Western Springs College Principal's Annual Report 2008. Western Springs College. Auckland. Retrieved from http://www.westernsprings.school.nz/WesternSpringsCollege_BoardOfTrustees/Principal \%20Annual\%20Report/WesternSpringsCollegePrincipal_AnnualReport2008.pdf

Hawe, P. (1994). Capturing the meaning of 'community' in community intervention evaluation: Some contributions from community psychology. Health Promotion International, 9(3), 199-210. doi: 10.1093/heapro/9.3.199

Healy, M., \& Perry, C. (2000). Comprehensive criteria to judge validity and reliability of qualitative research within the realism paradigm. Qualitative Market Research: An International Journal, 3(3), 118-126.

Hemmelgarn, A. L., Glisson, C., \& James, L. R. (2006). Organizational culture and climate: Implications for services and interventions research. Clinical Psychology: Science and Practice, 13(1), 73-89.

Hockley, J., \& Froggatt, K. (2006). The development of palliative care knowledge in care homes for older people: The place of action research. Palliative Medicine, 20(8), 835-843.

Hurrelmann, K., \& Raithel, J. (2005). Risk behavior in adolescence: The relationship between developmental and health problems. International Journal of Adolescence and Youth, 12, 281-299.

Israel, B. A., Schulz, A. J., Parker, E. A., \& Becker, A. B. (1998). Review of community-based research: Assessing partnership approaches to improve public health. Annual Review of Public Health, 19(1), 173-202.

Jennings, L. B., Parra-Medina, D. M., Messias, D. K., \& McLoughlin, K. (2006). Toward a critical social theory of youth empowerment. Journal of Community Practice, 14(1/2), 31-55.

Jones, M., Yonezawa, S., Ballesteros, E., \& Mehan, H. (2002). Shaping pathways to higher education. Educational Researcher, 31(2), 3-11.

Kelly, P. J. (2005). Practical suggestions for community interventions using participatory action research. Public Health Nursing, 22(1), 65-73.

Kemmis, S., \& McTaggart, R. (1988). The action research planner. Victoria, Australia: Deakin University.

Kemmis, S., \& Wilkinson, M. (1998). Participatory action research and the study of practice. In B. Atweh, S. Kemmis \& P. Weeks (Eds.), Action Research in Practice: Partnerships for Social Justice in Education (pp. 21-36). London: Routledge. 
Kilian, T., \& Yates, S. (2013). Western Springs College Waste Minimisation Project. Auckland: Waste Not Consulting

Klesges, L. M., Estabrooks, P. A., Dzewaltowski, D. A., Bull, S. S., \& Glasgow, R. E. (2005). Beginning with the application in mind: Designing and planning health behavior change interventions to enhance dissemination. Annals of Behavioral Medicine, 29(2), 66-75.

Labonte, R. (1994). Health promotion and empowerment: Reflections on professional practice. Health Education \& Behavior, 21(2), 253-268. doi: 10.1177/109019819402100209

Larson, R., \& Angus, R. (2011). Adolescents' development of skills for agency in youth programs: Learning to think strategically. Child Development, 82(1), 277-294. doi: $10.1111 / \mathrm{j} .1467-8624.2010 .01555 . x$

Larson, R., Walker, K., \& Pearce, N. (2005). A comparison of youth-driven and adult-driven youth programs: Balancing inputs from youth and adults. Journal of Community Psychology, 33(1), 57-74. doi: 10.1002/jcop.20035

Lenhart, A., Purcell, K., Smith, A., \& Zickuhr, K. (2012). Social media \& mobile Internet use among teens and young adults. Washington, DC: PEW Research Center.

Lewin, K. (1946). Action research and minority problems. Journal of Social Issues, 2(4), 34-46. Lietz, C. A. (2004). Resiliency based social learning: A strengths based approach to residential treatment. Residential Treatment for Children \& Youth, 22(2), 21-36.

Linley, P. A., Bhaduri, A., Sharma, D. S., \& Govindji, R. (2011). Strengthening underprivileged communities: Strengths-based approaches as a force for positive social change in community development. In R. Biswas-Diener (Ed.), Positive Psychology as Social Change (pp. 141-156). Berlin: Springer.

Lombardo, C., Zakus, D., \& Skinner, H. (2002). Youth social action: Building a global latticework through information and communication technologies. Health Promotion International, $17(4), 363-371$.

Mattessich, P. W., \& Monsey, B. R. (1992). Collaboration: What makes it work. A review of research literature on factors influencing successful collaboration. St. Paul, MN: Amherst Wilder Foundation.

Montoya, M. J., \& Kent, E. E. (2011). Dialogical action: Moving from community-based to community-driven participatory research. Qualitative Health Research, 21(7), 10001011.

Moreno, L., Henauw, S. D., Gonza'lez-Gross, M., Kersting, M., Molna'r, D., Gottrand, F., . . . Marcos, A. (2008). Design and implementation of the healthy lifestyle in Europe by nutrition in adolescence cross-sectional study. International Journal of Obesity, 32, 4-11.

Park, P. (2006). Knowledge and participatory research. In P. Reason \& H. Bradbury (Eds.), Handbook of Action Research (pp. 83-93). London: Sage. 
Peel, H. A., Peel, B. B., \& Baker, M. E. (2002). School/university partnerships: A viable model. International Journal of Educational Management, 16(7), 319-325.

Phillips, D. K., Harris, G., \& Larson, M. L. (2009). Trying on-being in-becoming four women's journey (s) in feminist poststructural theory. Qualitative Inquiry, 15(9), 1455-1479.

Rappaport, J. (1981). In praise of paradox: A social policy of empowerment over prevention. American Journal of Community Psychology, 9(1), 1-25.

Rush, K. L., Kee, C. C., \& Rice, M. (2005). Nurses as imperfect role models for health promotion. Western Journal of Nursing Research, 27(2), 166-183.

Saleebey, D. (1996). The strengths perspective in social work practice: Extensions and cautions. . Social Work, 41, 295-305.

Saleebey, D. (2000). Power in the people: Strengths and hope. Advances in Social Work, 1(2), 127-136.

Sandlin, R. A., \& Feigen, S. (1995). Collaboration between the university and school district: Can it work? Teacher Education Quarterly, Fall 1995, 75-82.

Schultz, P. W. (1998). Changing behavior with normative feedback interventions: A field experiment on curbside recycling. Basic and Applied Social Psychology, 21(1), 25-36. doi: $10.1207 /$ s15324834basp2101_3

Schultz, P. W., Nolan, J. M., Cialdini, R. B., Goldstein, N. J., \& Griskevicius, V. (2007). The constructive, destructive, and reconstructive power of social norms. Psychological Science, 18(5), 429-434.

Sharma, S. (2009). Where do we stand? One Auckland secondary school's journey towards environmental sustainability: A systems approach. Master's thesis, University of Auckland.

Simons, T. (2002). Behavioural integrity: The perceived alignment between managers' words and deeds as a research focus. Organization Science, 13(1), 18-35.

Starks, H., \& Trinidad, S. B. (2007). Choose your method: A comparison of phenomenology, discourse analysis, and grounded theory. Qualitative Health Research, 17(10), 13721380.

Stewart, T., \& Alrutz, M. (2012). Meaningful relationships: Cruxes of university-community partnerships for sustainable and happy engagement. Journal of Community Engagement and Scholarship, 5(1), 44-55.

Strand, K., Marullo, S., Cutforth, N., Stoecker, R., \& Donohue, P. (2003). Principles of best practice for community-based research. Michigan Journal of Community Service Learning, 9, 5-15. 
Suarez-Balcazar, Y., Davis, M. I., Ferrari, J., Nyden, P., Olson, B., Alvarez, J., . . . Toro, P. (2004). University-community partnerships: A framework and an exemplar.

Suarez-Balcazar, Y., Harper, G. W., \& Lewis, R. (2005). An interactive and contextual model of community-university collaborations for research and action. Health Education and Behaviour, 32, 84-101. doi: 10.1177/1090198104269512

Sussman, R., \& Gifford, R. (2011). Be the change you want to see: Modeling food composting in public places. Environment and Behavior. doi: 10.1177/0013916511431274

Tschannen-Moran, M., \& Tschannen-Moran, B. (2011). Taking a strengths-based focus improves school climate. Journal of School Leadership, 21(3), 422-448.

Van Manen, M. (1990). Researching lived experience: Human science for an action sensitive pedagogy. Albany: State University of New York Press.

Wolff, T. (2000). Practitioners' perspectives. In J. Rappaport \& E. Seidman (Eds.), Handbook of Community Psychology (pp. 741-777). New York: Plenum Publishers.

Wong, N. T., Zimmerman, M. A., \& Parker, E. A. (2010). A typology of youth participation and empowerment for child and adolescent health promotion. American Journal of Community Psychology, 46(1-2), 100-114. doi: http://dx.doi.org/10.1007/s10464-0109330-0

Woodhill, J., \& Röling, N. (1998). The second wing of the eagle: The human dimension in learning our way to more sustainable futures. In N. G. Roling \& M. A. E. Wagemakers (Eds.), Facilitating sustainable agriculture: Participatory learning and adaptive management in times of environmental uncertainty (pp. 46-71). Cambridge: Cambridge University Press.

Zimmerman, M. A. (1995). Psychological empowerment: Issues and illustrations. American Journal of Community Psychology, 23(5), 581-599. 
Appendix 1. Typical questions used in the school participant interviews

\begin{tabular}{|c|c|}
\hline Principle & Interview questions \\
\hline Strengths-based & $\begin{array}{l}\text { The team has tried to work with people in the school who are } \\
\text { themselves keen to forward sustainability. Do you think they } \\
\text { succeeded in doing that? The team also attempted to use the arts } \\
\text { and media as strengths of the school. Do you think they succeeded } \\
\text { in doing that? }\end{array}$ \\
\hline Empowerment & $\begin{array}{l}\text { The team aimed to help people achieve change but without imposing } \\
\text { their own ideas about how that change could happen. Do you feel } \\
\text { that they achieved that? What do you think the young people } \\
\text { involved learnt about how to effect positive sustainability changes? }\end{array}$ \\
\hline Role modeling & $\begin{array}{l}\text { The research team has tried to role model sustainable practices in } \\
\text { the project. Have you noticed that? What are you aware of that } \\
\text { they've tried to do? Do you think their attempt to "walk the talk" } \\
\text { helped the project? }\end{array}$ \\
\hline Communication & $\begin{array}{l}\text { How do you feel about the communication channels between } \\
\text { members of the school community and the research team? Is there } \\
\text { anything you can comment on about how they can be improved? }\end{array}$ \\
\hline $\begin{array}{l}\text { Measurement } \\
\text { and Feedback }\end{array}$ & $\begin{array}{l}\text { Are you aware of ways the team has tried to measure and } \\
\text { understand the sustainability culture of the school or the impact of } \\
\text { the project? Are you aware of feedback the team has given the } \\
\text { school about what they've measured? Do you have any comments on } \\
\text { what they did well and how they could improve? }\end{array}$ \\
\hline
\end{tabular}

